\title{
Dynamic daylight control system implementing thin cast arrays of polydimethylsiloxane-based millimeter-scale transparent louvers
}

\section{Citation}

Park, Daekwon, Philseok Kim, Jack Alvarenga, Keojin Jin, Joanna Aizenberg, and Martin Bechthold. 2014. "Dynamic Daylight Control System Implementing Thin Cast Arrays of Polydimethylsiloxane-Based Millimeter-Scale Transparent Louvers." Building and Environment 82 (December): 87-96. doi:10.1016/j.buildenv.2014.07.016.

\section{Published Version}

doi:10.1016/j.buildenv.2014.07.016

\section{Permanent link}

http://nrs.harvard.edu/urn-3:HUL.InstRepos:37255347

\section{Terms of Use}

This article was downloaded from Harvard University's DASH repository, and is made available under the terms and conditions applicable to Open Access Policy Articles, as set forth at http:// nrs.harvard.edu/urn-3:HUL.InstRepos:dash.current.terms-of-use\#OAP

\section{Share Your Story}

The Harvard community has made this article openly available.

Please share how this access benefits you. Submit a story.

Accessibility 


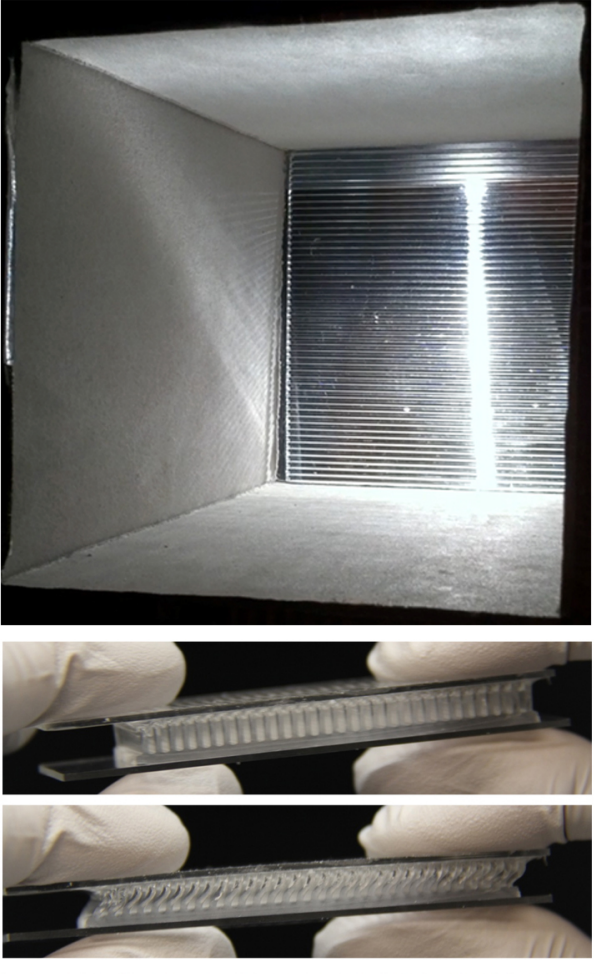

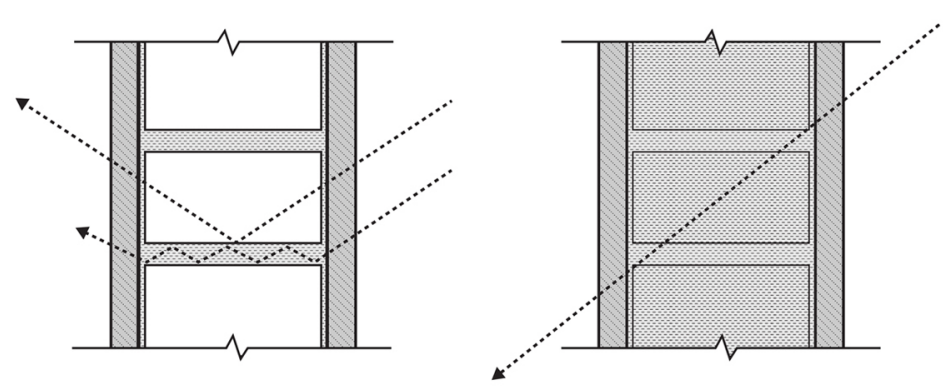

Light redirection state
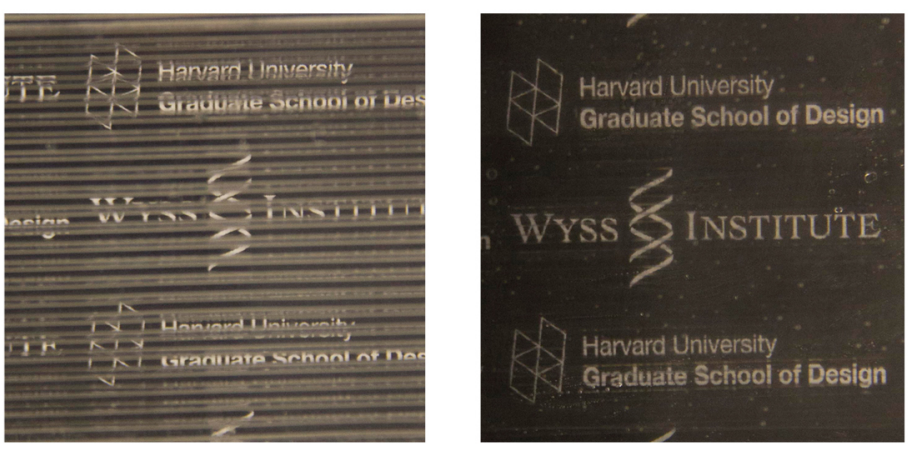

Transparent state

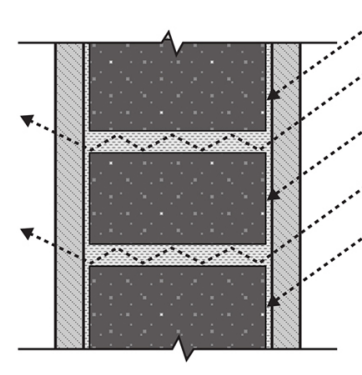

Shading state

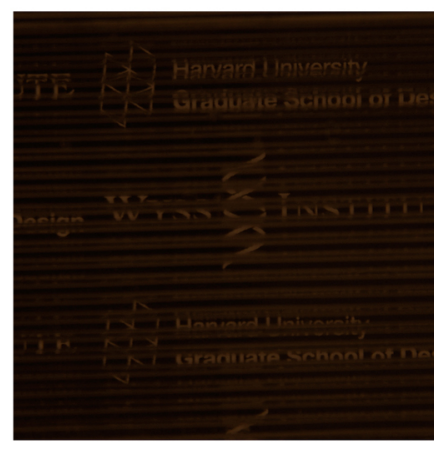

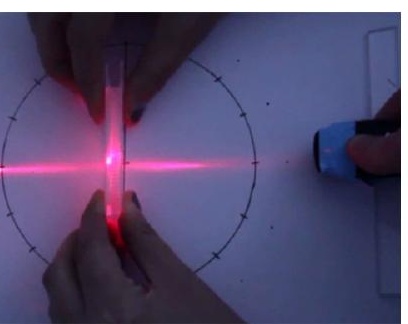
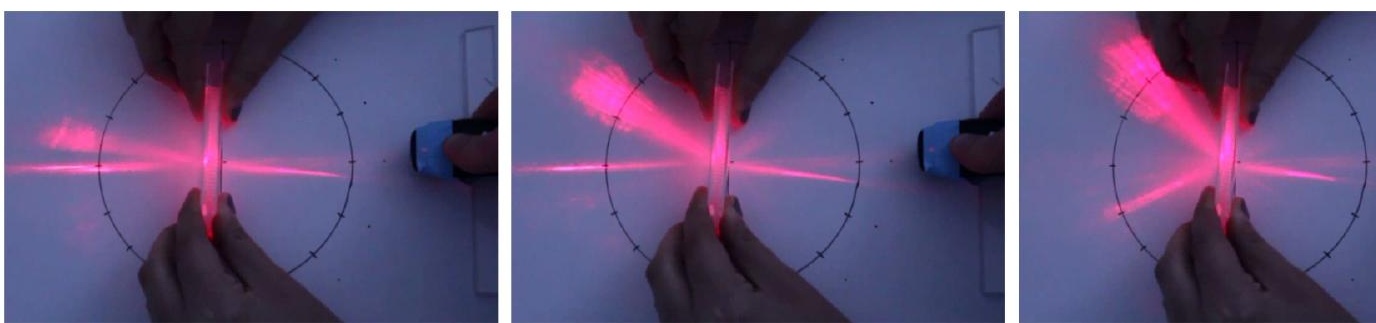


\title{
Dynamic daylight control system implementing thin cast arrays of polydimethylsiloxane-based millimeter-scale transparent louvers
}

\author{
Daekwon Park $^{\mathrm{a}, \S}$, Philseok Kim ${ }^{\mathrm{b}, \S, *}$, Jack Alvarenga ${ }^{\mathrm{b}}, \mathrm{K}$ Keojin Jin ${ }^{\mathrm{a}}$, Joanna Aizenberg ${ }^{\mathrm{b}}$, Martin \\ Bechthold ${ }^{\mathrm{a}, \mathrm{b} *}$ \\ ${ }^{a}$ Harvard Graduate School of Design, 48 Quincy St, Cambridge, MA 02138, USA \\ ${ }^{b}$ Wyss Institute for Biologically Inspired Engineering at Harvard University, 3 Blackfan Cir., Boston, MA 02115, USA \\ ${ }^{\S}$ These authors contributed equally to this work. \\ *Corresponding Authors: \\ Prof. Martin Bechthold: mbechthold@gsd.harvard.edu, 617-495-6012, Harvard Graduate School of Design, 48 Quincy \\ Street, Cambridge MA 02138, USA \\ Dr. Philseok Kim: philseok.kim@wyss.harvard.edu, 617-495-2641, Wyss Institute for Biologically Inspired Engineering at \\ Harvard University, 60 Oxford St., Cambridge, MA 02138, USA
}

\begin{abstract}
The deep building layouts typical in the U.S. have led to a nearly complete reliance on artificial lighting in standard office buildings. The development of daylight control systems that maximize the penetration and optimize the distribution of natural daylight in buildings has the potential for saving a significant portion of the energy consumed by artificial lighting, but existing systems are either static, costly, or obstruct views towards the outside. We report the Dynamic Daylight Control System (DDCS) that integrates a thin cast transparent polydimethylsiloxane (PDMS)-based deformable array of louvers and waveguides within a millimeter-scale fluidic channel system. This system can be dynamically tuned to the different climates and sun positions to control daylight quality and distribution in the interior space. The series of qualitative and quantitative tests confirmed that DDCS exceeds conventional double glazing system in terms of reducing glare near the window and distributing light to the rear of the space. The system can also be converted to a visually transparent or a translucent glazing by filling the channels with an appropriate fluid. DDCS can be integrated or retrofitted to conventional glazing systems and allow for diffusivity and transmittance control.
\end{abstract}

Keywords: Daylight control system, dynamic window system, energy-efficiency, transparent louvers 


\section{Introduction}

Daylighting in buildings has direct and indirect impact on the quality of space, health of the occupants, and energy efficiency of the building. Compared with artificial lighting, daylighting provides an ideal color rendering environment, as well as psychological and physiological benefits for the occupants $[9,11,12,34]$. Improving the daylighting performance of buildings also contributes in reducing the need for artificial lighting with improved distribution of daylight throughout the interior space [21]. According to the US Energy Information Administration data published in 2011, the overall building sector accounts for 41 percent of the total U.S. primary energy [7]. Furthermore, the U.S. Energy Information Administration's (USEIA) annual energy review from 2005 states that 54 percent of the total energy used by commercial buildings in the US is in the form of electricity. Among that portion, 24 percent of the electricity is being used for artificial lighting. Therefore, reducing the artificial lighting consumption through daylighting strategies has significant impact on the overall reduction of energy consumption.

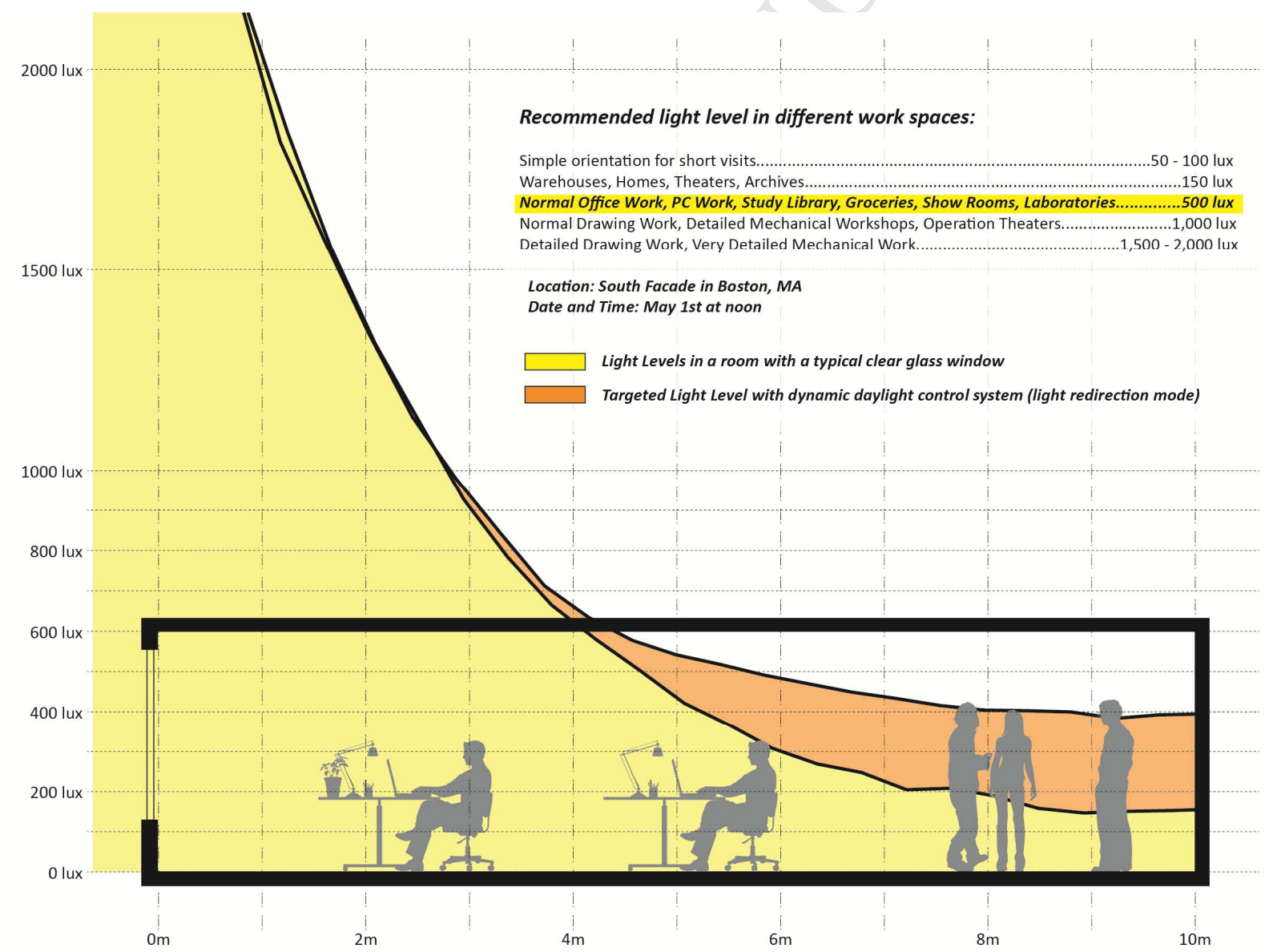

Fig. 1 Targeted daylight level distribution within a typical office space using Dynamic Daylight Control System (DDCS).

Daylight autonomy is a widely recognized criterion for measuring the degree to which interior spaces are sufficiently lit without artificial lighting [28]. One of the key goals of daylight control systems is to 
improve daylight autonomy by maximizing the daylight level at the rear of the space, which increases the time where interior zones of the building are above a target minimum illuminance level (see Fig.1). The required minimum illuminance levels vary depending on the intended use of the space [6] and are summarized in Fig. 1. In order to achieve a maximum amount of Daylight Autonomy, it is also necessary to minimize glare by lowering excessive lighting levels near the window. Doing so eliminates the need for occupants near the windows to close blinds or other operable shading systems [23], which in turn lowers lighting levels deeper in the space. Typical criteria used for evaluating a daylight control system comprise of shading capability, glare protection, unobstructed view toward the outside, light guidance into the depth of the room, homogeneous illumination/light distribution, energy-saving potential, tracking requirements, dynamic adjustment capability for transient solar condition, and the availability of the system as a product $[3,11,12,16$, $17,29,33]$.

\subsection{Existing Daylighting Systems}

Typical daylight control strategies include light transmission control, light redirection, and light transportation. Light transmission control strategies shade, scatter, and/ or diffuse excess sunlight transmission that creates local discomfort from glare or uneven daylight distribution. Common light transmission control systems include louvers, overhangs, blinds, draperies, and glazing augmentation (e.g. surface coatings, films, and insertions) [3, 11, 12, 24, 29]. On the other hand, light redirecting strategies are used to refract light into the unlit areas to improve the daylight penetration. Systems that utilize this strategy include light shelves, anidolic mirrors, and prismatic panels [33]. Finally, light transportation strategies collect sunlight and guide it over a long distance where there is limited or no access to daylight. Typical systems and devices include light pipes, fiberoptics, heliostats, and solar tubes [24, 33].

The daylighting systems that utilize these strategies can be classified into static systems and dynamic systems. Static daylighting systems are typically simple, affordable, and easier to implement and maintain than dynamic daylighting systems. However, since they are passive systems, the capability to address the solar elevation angle changes and sky conditions is limited. On the contrary, dynamic systems can be actively controlled based on the solar elevation angle and sky conditions, as well as occupant comfort preferences. This capability not only increases the productivity and well-being of the occupants by adaptively enhancing the visual and thermal comfort, but also substantially reduces the energy usage of the building $[2,24,26,27]$. It is reported that by combining a dynamic daylight system with automated artificial lighting control, it is possible to save from 30 to 77 percent of the lighting energy $[13,30]$.

However, there are also limitations and challenges that dynamic daylighting systems need to overcome. Dynamic systems typically utilize components that are often sensitive and delicate such 
as sensors, actuators, control elements, and hinges, etc. These extra components not only increase the cost of the system and reduce the robustness of the system, but also cause complications in operating and maintaining them [24]. Furthermore, due to the subtle differences of comfort preferences and behavioral patterns among individuals, there are challenges in implementing flexible, efficient, and reliable control. There have been a number of studies that investigate these issues which highlight the importance of view outside, sense of control over automated control, as well as the frequency and speed of the daylighting configuration transitions [2, 25].

With the development of new innovative materials with adaptive or tunable attributes as well as the advancement of control and automation methods utilizing physical sensors and artificial intelligence, the disadvantages of both static and dynamic daylighting systems are being overcome [20]. In this milieu, various innovative daylighting systems that improve or combine the conventional techniques are increasingly being researched, developed, and commercialized [24]. The various examples of innovative daylighting systems are categorized and presented in the following based on light transmission control systems, light redirection systems, and light transportation systems.

Innovations in light transmission control systems include dynamic shading devices and dynamically tinted smart windows. Various types of exterior, interior, or embedded automated blinds and motorized roller shades that actively minimize direct sunlight and maximize daylighting in targeted zones are now available commercially. The energy efficiency and control methods of these systems are actively being studied as well $[14,19,31]$. Dynamically tinted smart windows can change from transparent to tinted states, which can mediate solar factor and radiation based on electric current or environmental changes (e.g. temperature and/or light). The most common systems include chromic devices (electrochromic, gasochromic, photochromic and thermochromic), liquid crystal devices, and suspended-particle devices $[1,4,8]$.

On the other hand, innovations in light redirection systems include static systems, such as films and embedded systems, as well as dynamic systems that utilize adaptive strategies. Innovative static systems include sun-directing glasses that are essentially transparent microstructured systems (e.g. concave louvers, prismatic structures) that can be embedded in double glazing window systems. Using the same principle, this system can be further scaled down to a film that can be directly applied to the window itself $[11,12]$. Innovative dynamic systems include light shelves, micro scale mirrors, and reflective elements that can change its angle and/or geometry based on environmental conditions or occupant preferences $[11,12,22,27]$.

Finally, innovations in light transportation systems include combining several conventional systems and material technologies for more versatile application as well as integrating dynamic tracking capability to the light collector. Some examples of commercially available systems include the Sunportal ${ }^{\mathrm{TM}}$ daylighting system which combines the Heliostat technology with sunlight concentrator, 
optical relay lenses, and transparent tube diffuser; the SunCentral System ${ }^{\mathrm{TM}}$ which redirects sunlight into the interior space using arrays of active mirrors, curved mirrors, and highly reflective films; and the Parans ${ }^{\mathrm{TM}}$ system which utilizes dynamic solar receivers augmented by Fresnel lenses, quartz optical fibers, and various types of customized solar luminaires [15, 24].

\subsection{Comparison between existing daylighting systems and DDCS}

Among the existing daylighting systems, several typical systems are selected and compared with the DDCS (see Fig. 2). Since each daylighting system is engineered to provide optimum performance for a limited number of aspects of daylighting, several systems are often required to be used in combination in order to achieve the desired overall condition. Such limitations can lead to the installation of redundant multi-layered systems that are potentially costly, difficult to maintain, and visually disturbing when not in use. For instance, a combination of prisms and blinds or a combination of louvers and blinds can simultaneously control shading, glare, and light distribution. However, these systems compromise cost-effectiveness, obstruct views towards the outside, and reduce daylight autonomy.

Furthermore, existing daylighting systems are often static, or only capable of limited adjustability, due to the cost and maintenance requirements of dynamic systems. Exterior mounted dynamic and retractable louver systems, for example, are effective in both controlling the lighting levels as well as minimizing the excessive solar heat gain, but are costly and sensitive to weathering and wind damage. Existing systems that reside in the cavity of a double-glazed unit are better protected from the external factors, but they are usually static, require vulnerable mechanical hinges, permanently obstruct views, and may reduce the insulation qualities of the double-glazed unit. Consequently, a minimalistic and simple solution that can combine various daylighting strategies with the capability to dynamically adjust the redirection angle and control diffusivity and visual transparency of the glazing reacting to the transient behavior of the solar movement and the sky cover is desirable.

This research describes a multi-functional yet simple Dynamic Daylight Control System (DDCS) composed of integrated millimeter scale transparent light reflectors and guides that can be dynamically adjusted in relation to the sun angle. The prototypical system consists of an array of small deformable louvers made of a transparent silicone elastomer, polydimethylsiloxane (PDMS), which refract and guide light. PDMS is a highly transparent $(\lambda \geq 300 \mathrm{~nm})$, durable, hydrophobic, nontoxic, biocompatible, and chemically inert material with excellent stability against degradation by ozone and UV. For this reason, PDMS has been used as long-term, reliable protection materials for circuits and electronic components, barriers against contaminations such as acids and bases, durable dielectric insulation, and shock and vibration absorbing materials to relieve stress with a wide range of operation temperature $\left(-45^{\circ} \mathrm{C}\right.$ to $\left.200^{\circ} \mathrm{C}\right)$ and humidity. In addition, it has been widely used as a prototyping material for microfluidics, micro-optical devices, and lab-on-a-chip devices and can be 
bonded to itself or to other materials. Since DDCS utilizes transparent materials, the utilization of daylight is maximized. The system also features millimeter-sized fluidic or gas-filled channels to achieve desired diffusivity or visual transparency. By filling the interstitial space between the louvers with fluids that have different opacities, it is possible to diffuse or block the incoming daylight.

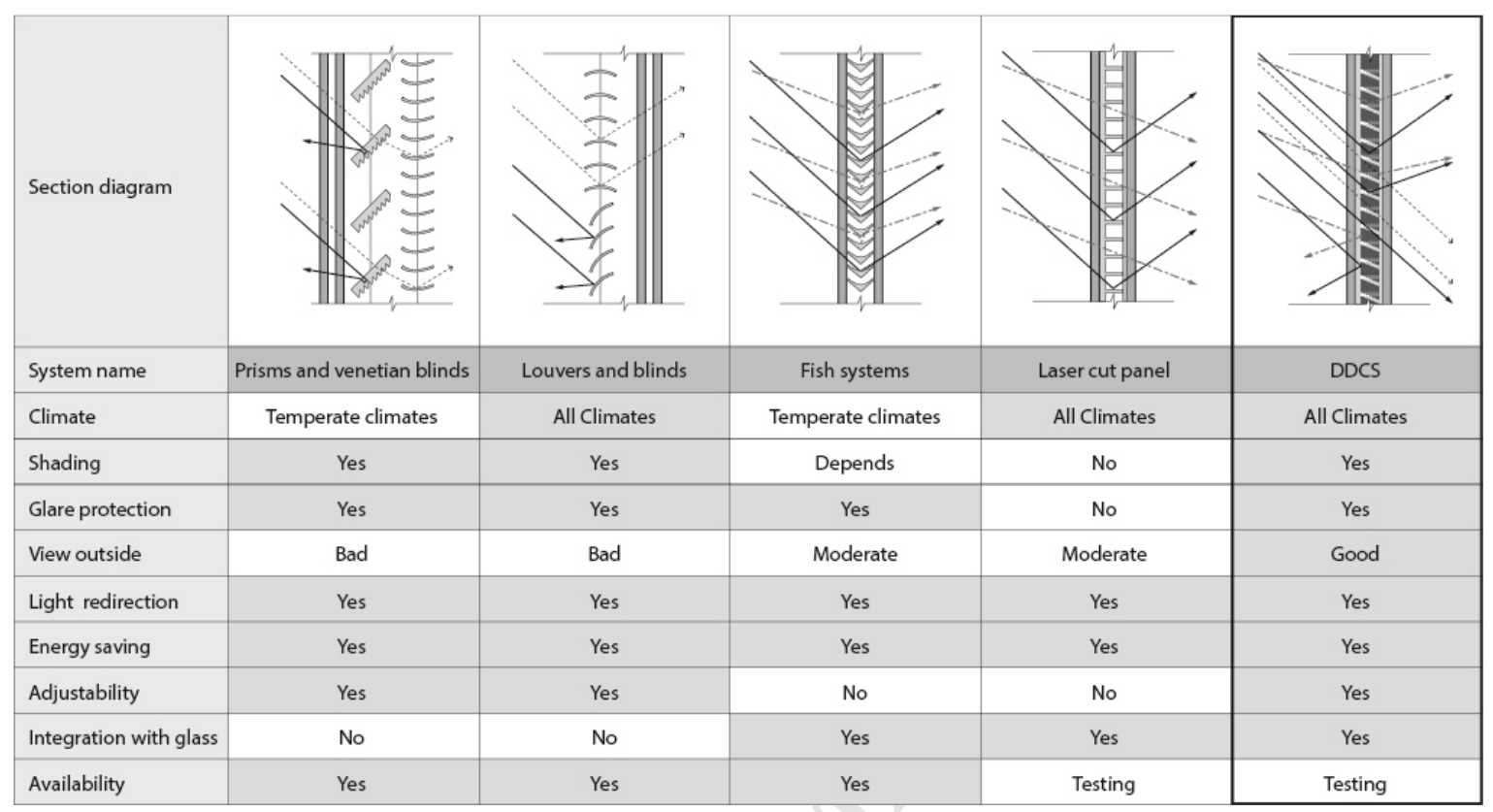

Fig. 2 Features of existing daylight control systems compared to the dynamic daylight control system.

\section{Materials and Methods}

\subsection{Design Principles}

The Dynamic Daylight Control System (DDCS) avoids the pitfalls of mechanically hinging blinds and louvers by relying exclusively on elastic deformations of millimeter-sized PDMS louvers. Located between and adhered to two stiff and optically clear materials, such as glass or acrylic, the PDMS louvers change shape when one of the outer stiff layers is displaced relative to the other layer (see Fig 6-a).

Light is redirected to the interior ceiling by reflecting off the PDMS louvers. From the ceiling, secondary reflections bounce light back towards the floor to create desired interior lighting levels. Light redirection takes place because the index of refraction of PDMS differs from that of the medium that fills the voids between the louvers (e.g. air in the case of empty channels). The relative difference of these two neighboring medium's refractive indices determines how much light is bent. When the index of refraction is matched across all media, the light passes directly through them as if 
it was made with one solid material. This interstitial space between the louvers is designed as part of a fluidic network which adds several functions not normally present in daylight redirection systems such as thermal control $[5,10]$. By deliberately adding and removing fluids with specific optical properties the system can be configured to transmit, redirect, or reduce light (Fig. 3 and Fig. 7) [32].

In the redirecting state (empty channels) shown in Fig. 3 (a) and Fig. 7 (a), the system is translucent with the PDMS louvers visible and partially blurring the view to the outside through the DDCS. In situations that do not require daylight redirection, a refractive index matching fluid can be pumped into the channel voids between louvers, rendering the system optically clear (Fig. 3 (b) and Fig. 7 (b)). In order to achieve a fully transparent state, a mixture of glycerol and water (57:43) that matches the refractive index of PDMS (1.43) was filled in the interstitial space.

In addition, sunlight can also be partially diffused or entirely blocked to achieve desired lighting levels or privacy requirements by filling a translucent or an opaque liquid into the channels (Fig. 3 (c) and Fig. 7 (c)). In order to achieve these different levels of translucencies, light absorbing liquid with varied amount of ink mixed with water was filled in the interstitial space which makes the window appear tinted. Based on the opacity of the liquid used, the sample can either block light entirely or diffuse light. The combination of the three states makes DDCS unique compared to existing daylight control solutions which often utilizes several individual systems layered against each other to achieve these functionalities.

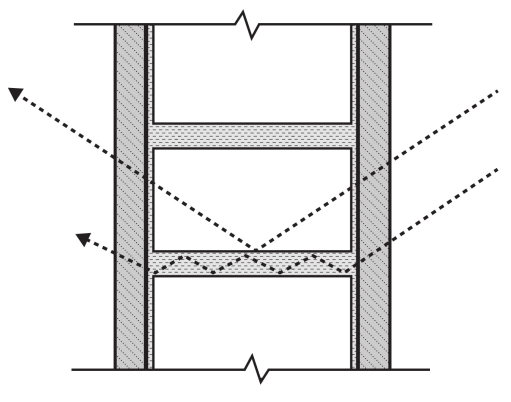

(a)

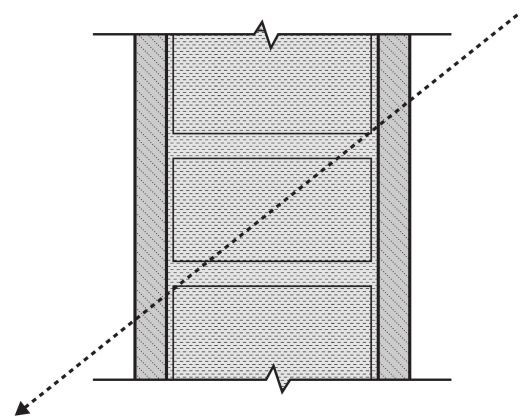

(b)

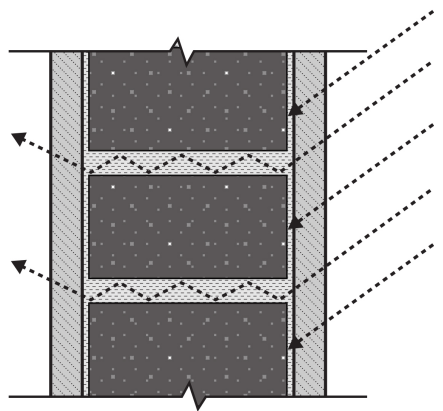

(c)

Fig. 3 Three distinct states of a dynamic daylight control system and their functions: (a) light redirection effect from empty channels by specular reflection and total internal reflection, (b) clear transparent glazing with fully or partially index matched liquid filled in the channels, and (c) diffusive/absorbing/dimming/coloring effect with particle suspended or pigmented liquid filled in the channels.

\subsection{Prototyping}

Multiple stages of prototyping confirmed the validity of redirecting light and the ability to control translucency and opacity by integrating selected fluids. The prototyping process consists of three primary steps: design of the louvers, casting the louvers, and mounting the louvers to glass panes. 


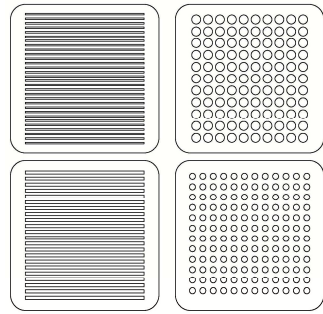

(a)

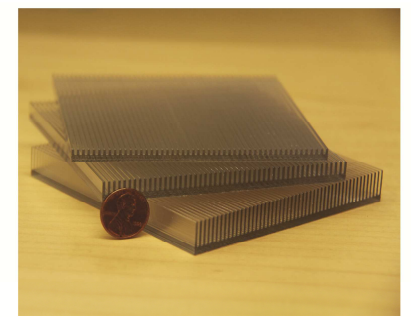

(b)

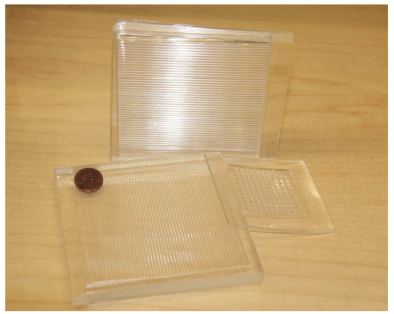

(c)

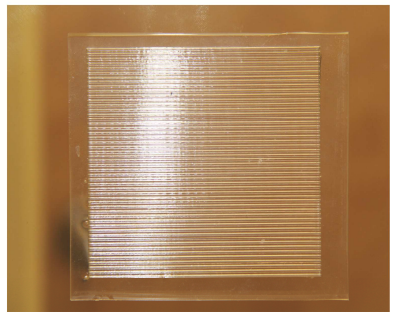

(d)

Fig. 4 Simple geometry prototyping process: (a) Example CAD drawings of designed patterns. (b) 3D printed mold. (c) Casted PDMS louver array. (d) PDMS louver array attached between two sheets of glass.

In the design stage, the geometry and pattern of the PDMS louvers were designed using Computer Aided Design (CAD) software. Depending on the complexity of the geometry, 2D and 3D drawings of the mold geometry were prepared (Fig. 4 (a)). Several iterations of the design were evaluated based on the size of the prototype, shape of base geometry, and the density of the pattern. Finally, the base drawing of the mold geometry was chosen and prepared for the next stage.

In the louver casting stage, a one-part mold was 3D printed (Objet Connex 500) from the designed CAD drawings (Fig. 4 (b)) and the two component PDMS (Dow Corning Sylgard 184 kit) was mixed (base resin weight: curing agent weight $=10: 1$ ) and poured into the prepared mold. After degassing under a vacuum for 2-4 hours, the cast mixture was thermally cured at $70^{\circ} \mathrm{C}$ for $4-6$ hours. After the curing process the cast was removed from the mold (Fig. 4 (c)).

Finally, the mounting stage involved coating a thin layer of PDMS on two sheets of glass or acrylic, attaching the PDMS louver system and repeating the curing process in the oven. The resulting DDCS prototype forms a fully integrated unit for testing the actuation and light redirection effect (Fig. 4 (d)).

\section{Results}

\subsection{Initial Testing}

A series of physical tests were conducted to evaluate the properties of the DDCS prototype. Initially, the basic behavior of light redirection was confirmed by visualizing reflections and light guide effects through laser projections at multiple incident angles. The sample with PDMS louvers in its default position (Fig.3) shows various ways of reacting against the light such as refraction, scattering, and guide effect (Fig. 5 (a)). Furthermore, by shearing the DDCS while the laser source is kept at a fixed position, the refracted light can be finely tuned to a desired angle (Fig. 5 (b)). Although the test is purely qualitative, it demonstrates the capability of the transparent PDMS louvers to dynamically 
refract light towards the intended directions. Since PDMS is a highly transparent material that is suitable for optical applications, the light transmission (including daylight) loss is negligible as long as the quality of the cured PDMS is high without air bubbles or dust encapsulated in the material.

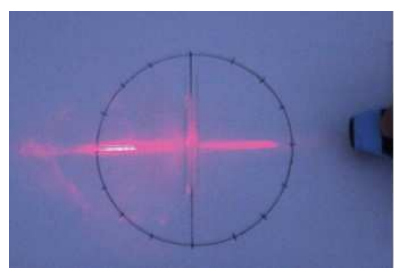

(a)

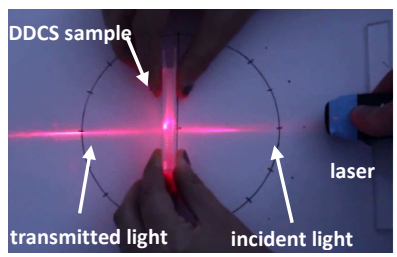

(b)
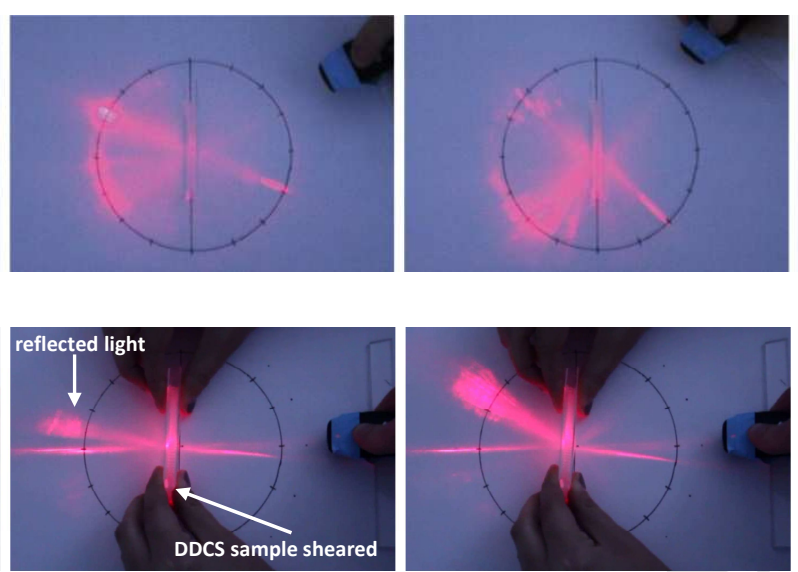
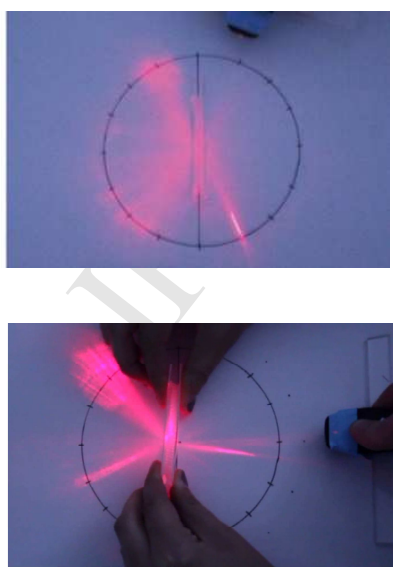

Fig. 5 DDCS prototype properties: (a) Demonstration of light redirecting effects (shown on the left-hand side of each picture) for various incident angles of a laser light (shown on the right-hand side of each picture) illuminated through a DDCS sample without shear. (b) Demonstration of light redirecting effects at a fixed incident angle of a laser light illuminated through DDCS sample undergoing shear deformation.

In order to analyze the deformation of the system during shearing actuation, both physical testing and finite element analysis (FEA) were conducted (Fig. 6). Both results show an S-curve deformation perpendicular to the displacement direction of the glass panes, in which the buckled elastomeric louvers provide stress-relief for the system. As seen in FEA in Fig. 6 (b), the maximum stress (red) is at the interface between the elastomeric louvers and the rigid glass panes. The deformation of the sheared PDMS louvers correspond to the amount of force and displacement applied to the sample and are consistent through various shearing cycles.
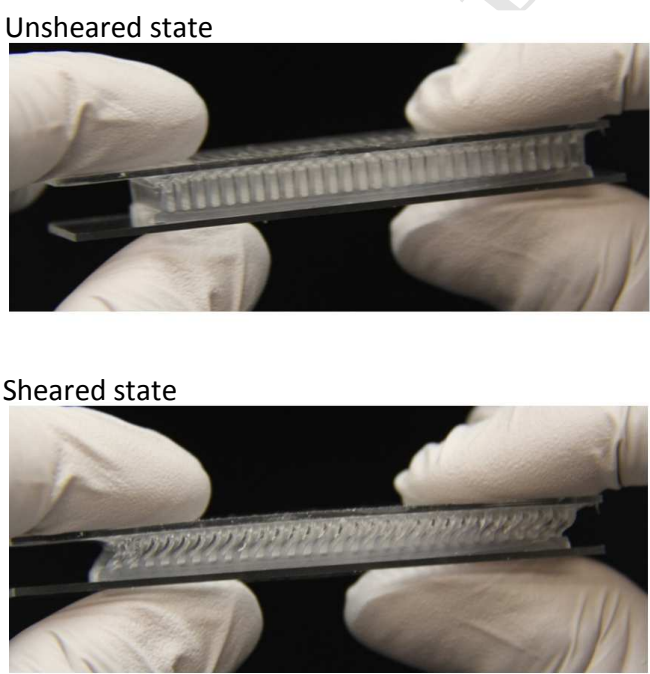

(a)

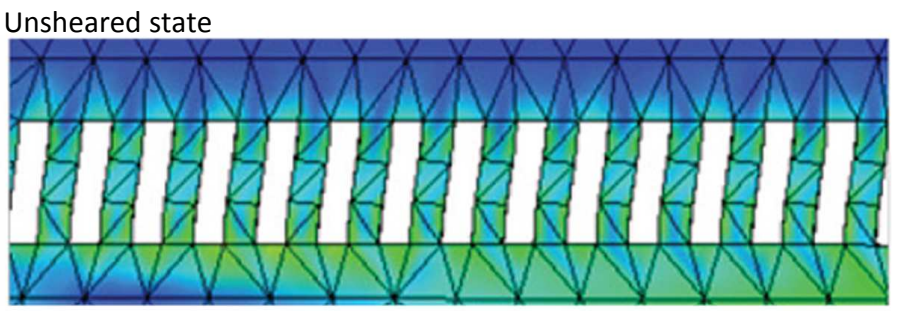

low stress

high stress

Sheared state

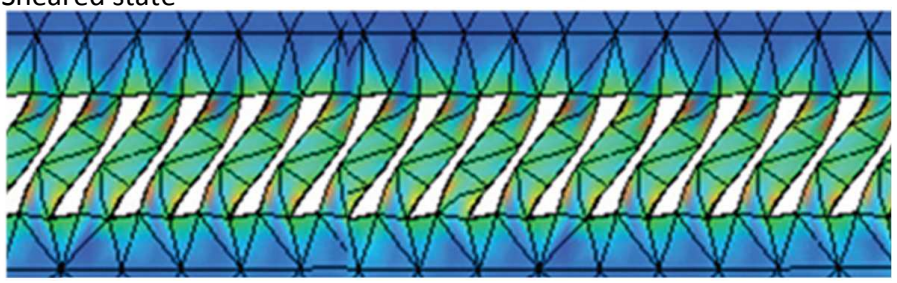

(b)

Fig. 6 DDCS deformation analysis: (a) Wide range of angles can be configured through shear-induced deformation of the PDMS louvers. (b) Finite element analysis simulation of unsheared state and sheared state PDMS louvers between two panes of glass. 
The optical tunability of DDCS using fluid infiltration was also investigated. The sample was tested in front of a dark backdrop with white text and logo in three different states and the effect is shown in Fig. 7. In the default state where the channels are empty (or air-filled), the PDMS louvers are visible and the backdrop information is partially visible (Fig. 7 (a)). In the index matching liquid filled condition, the louvers are nearly invisible and the backdrop information is clearly visible (Fig. 7 (b)). Lastly, in the pigmented liquid-filled condition, both the louvers and backdrop information is partially visible and tinted (Fig. 7 (c)). The sample can either block light entirely or diffuse light based on the opacity of the liquid used at the pigmented liquid filled state. Furthermore, the quality of the test sample in terms of surface finish, homogeneity of the PDMS, and attachment to the substrate can further improve the transparency of the system at the index matched liquid filled state.

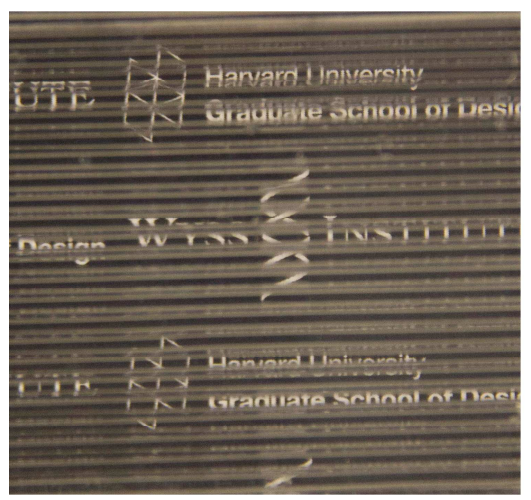

(a)

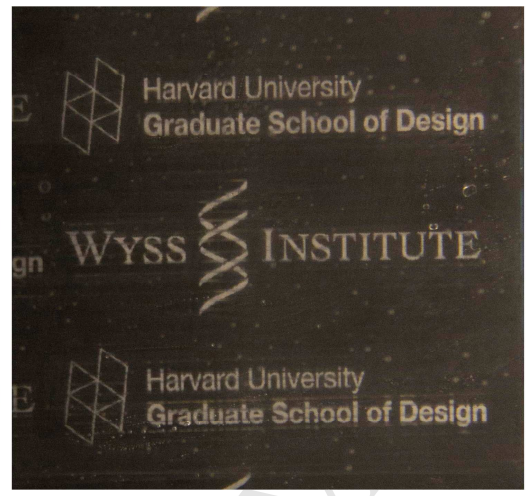

(b)

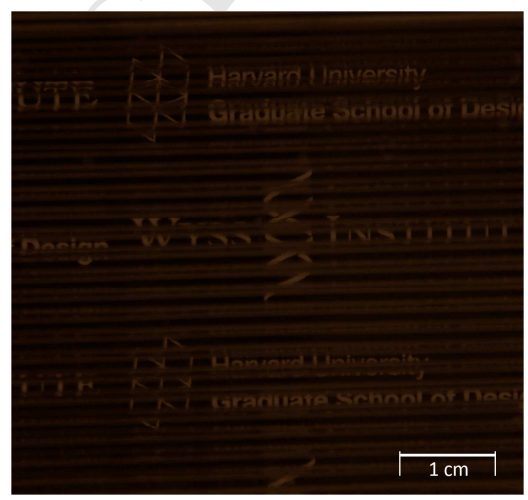

(c)

Fig. 7 Control of light passage and appearance of a DDCS sample with various filling media: (a) Air, (b) Index matched liquid, (c) Pigmented liquid filled in the channels. All photographs were taken under the same illumination condition.

Finally, a white box test was performed using a box (two sides open and the inner surfaces are colored white) with a DDCS sample mounted on one open side as shown in Fig. 8. The light source (a $150 \mathrm{~W}$ fiber optic halogen lamp) was held outside of the box and a video was taken from the opposite open side of the box. It is clearly visible that the incoming light is reflected by the DDCS sample and distributed along the top surface, side surface, and bottom surface (Fig. 8 bottom photographs). As the angle of the incident light source decreases, the depth of the reflected light projected onto the surfaces increases accordingly (Fig. 8 top diagrams). 

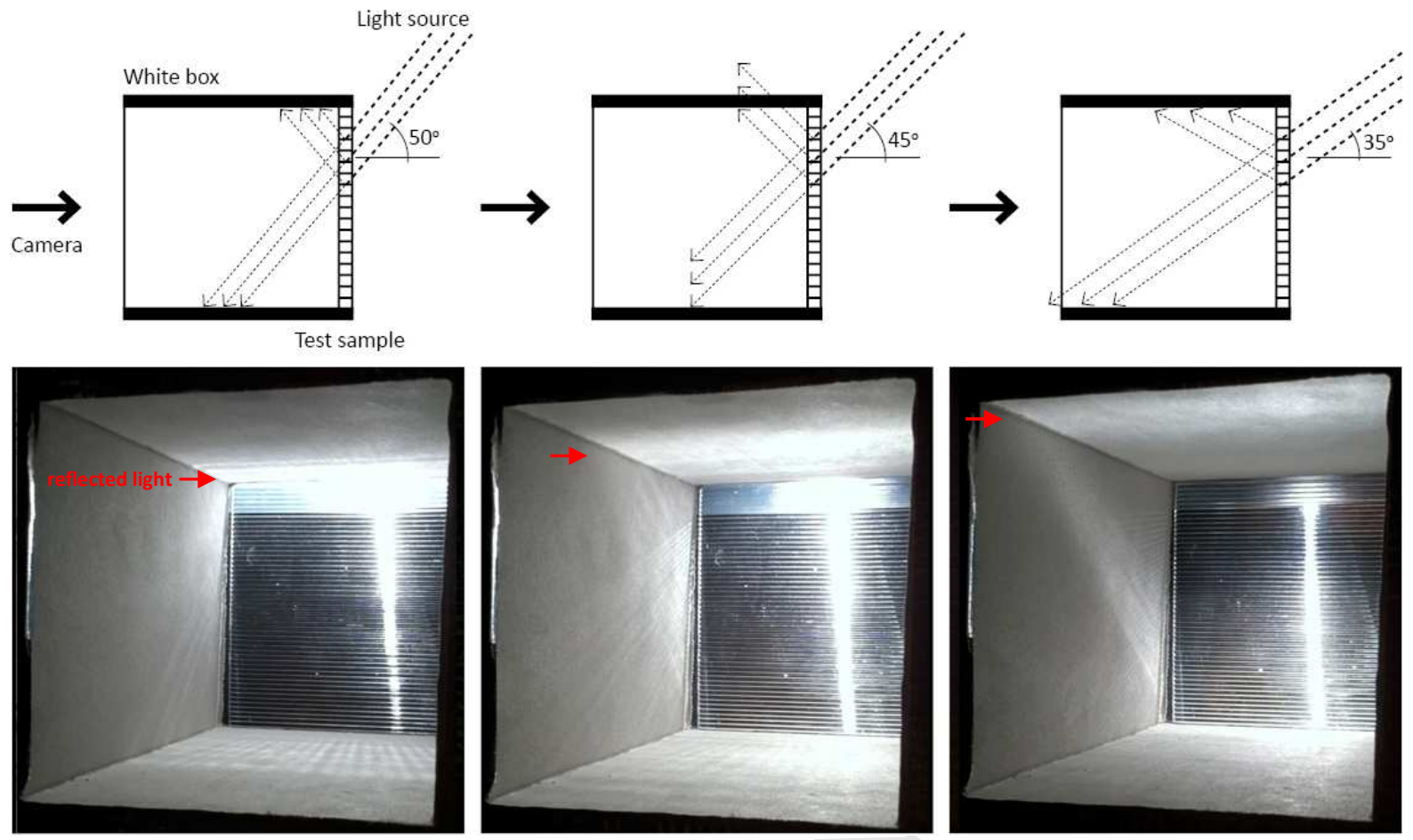

Fig. 8 White box test diagram and photograph corresponding to three different light source angle setup. The photographs clearly show the light redirection effect on the ceiling, wall and floor.

\subsection{Quantitative Tests on Light Redirection}

Following the initial proof-of-concept testing, several test setups were created to more specifically evaluate and measure the light redirection effect. The black tube testing consists of a forty-eight inches long hollow tube (two inches by two inches square opening at both sides) with a light source and a DDCS sample at one end and a light meter and video recording setup at the other open end (Fig. 9 (a)). The normal incidence reflectivity of the testing tube was measured to be an average of $3.7+/-0.2 \%$ across the visible spectrum (400-900 $\mathrm{nm}$ wavelength).

Without any sample in place, the light intensity at the entrance was measured to be 8900 Lux., This intensity was reduced to 1.8 Lux at the end of the tube. This value increased to 2.5 Lux when a clear double pane glass was inserted at the entrance of the black tube and further increased to a value between $\sim 75$ to $\sim 210$ Lux when the DDCS sample was inserted and actuated, respectively. A plot of the measured light intensities during the shearing actuation cycles of the DDCS sample is shown in Fig. 9 (b). The maximum light intensities were observed at specific shear angles (e.g. angle II, Fig. 9 (b)) where the louver redirects the maximum amount of the incoming light to the furthest length towards the light meter. Fig. 9 (c) visually shows the lighting conditions through the actuation process. 


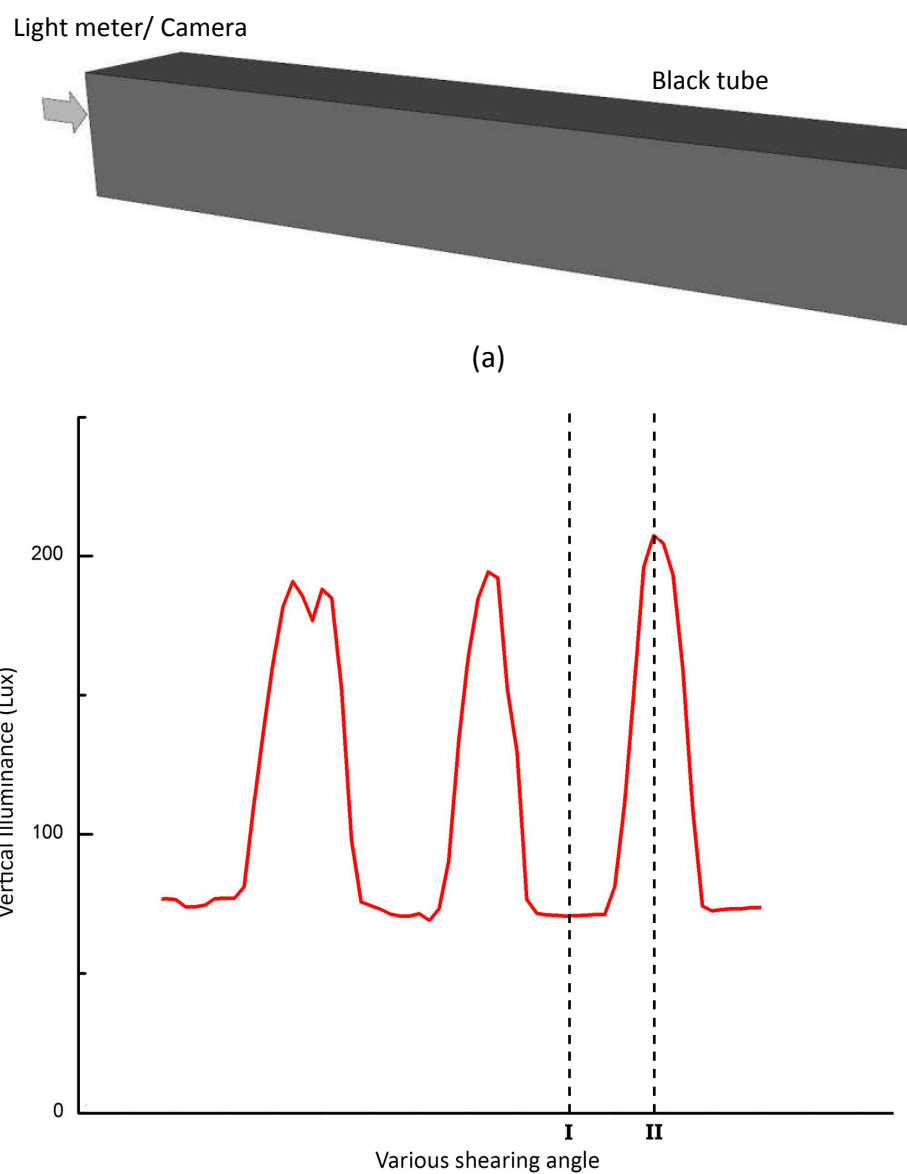

(b)
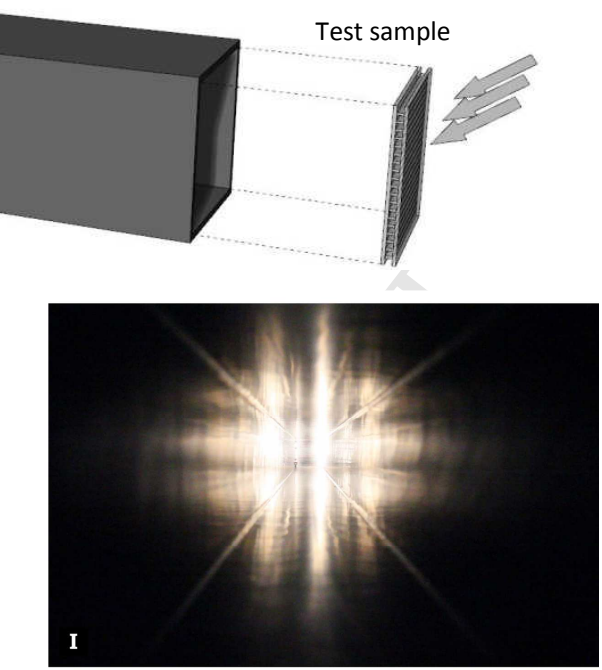

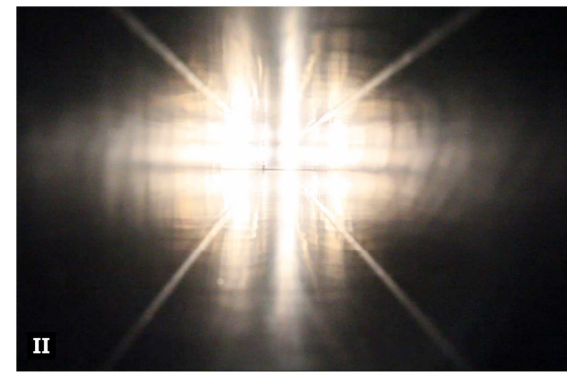

(c)

Fig. 9 Black tube testing setup and results (a) Black tube testing setup. (b) A graph of vertical illuminance value during three actuation cycles using black tube test setting. (c) Photographs of lighting effect recorded at shearing angle I and II shown in the graph.

The next testing iteration examined the ability of the DDCS to direct light to various depths inside another simulated dark, non-reflective environment (Fig. 10, 11). A wood box with light-absorbing matte black finish on the interior was constructed, and the intensity of the redirected light was measured using a light meter along the top surface (ceiling). This test setup was intended to measure only the first reflection of light from the DDCS sample to the ceiling without the influence of secondary reflection from the other surfaces. The location and set-up of the light source, test sample, and the light meter is diagramed in Fig. 10.

Fig. 11 (a) shows a plot of measured light intensity as a function of parallel distance from the lightfacing wall to the location of the light meter inside the shoebox. The measurement was repeated for four different opening conditions which consists of air (no test sample), blank (double glass sheets without DDCS), inactive (non-actuated DDCS), and active state (actuated DDCS sample). The measured data shows that when the DDCS is actuated, there is an approximatly 700 percent increase in daylighting over the double glass sheets without the DDCS. Furthermore, the amount of direct light at the base of the window which is the main cause of glare, is locally reduced and distributed across the bottom and top surfaces (Fig. 11 (b)). 


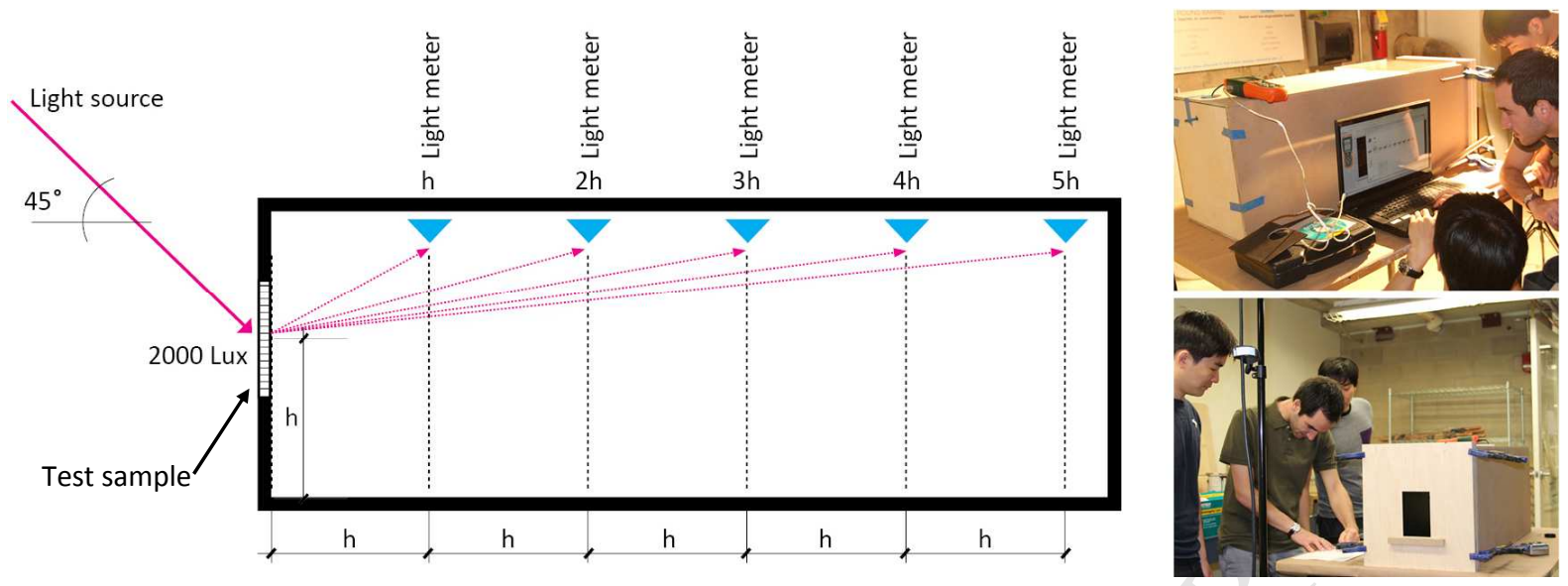

Fig. 9 Shoebox testing setup section diagram. The test sample is mounted on one side and the light source is projected on to the sample at a 45 degree angle (the illuminance level measured directly in front of the test sample is 2000 lux). The light meter is mounted on the top surface and can measure the first reflection of the light in various locations using a sliding mechanism.

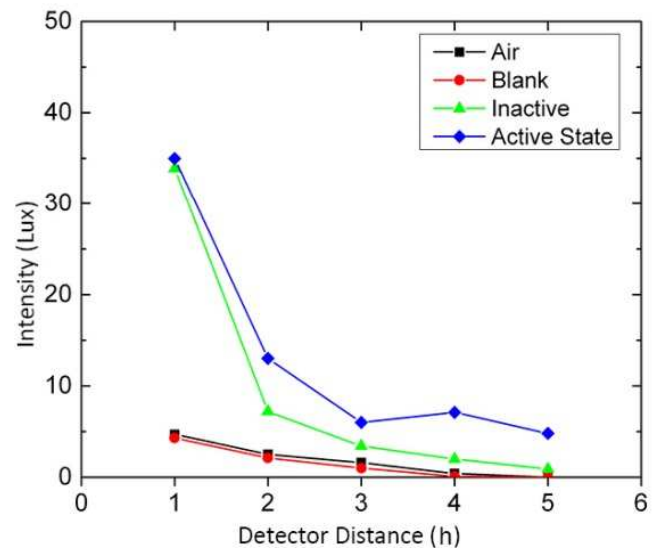

(a)
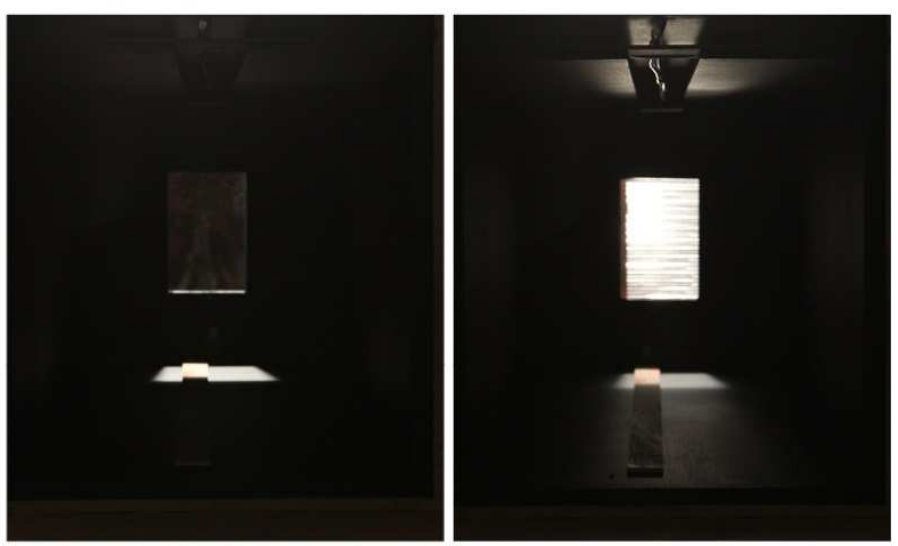

(b)

Fig. 10 Shoebox testing results. (a) air (no test sample), blank (double glass sheets without DDCS), inactive (non-actuated DDCS), and active state of the DDCS sample. (b) Photograph of the shoebox testing setup using double glass sheets (left) and active state DDCS (right). Compared to the left photograph, the right photograph clearly shows the light refraction effect to the top surface of the box as well as the reduction of direct light to the bottom surface of the box.

Yet another test involved the use of a table-top heliodon [35] to create simulated sun positions at latitude of $42.0^{\circ}$ North (Boston, USA) at noon on the $21^{\text {st }}$ of each month. At the center of the heliodon, a shoebox model $\left(8^{\prime \prime} \times 8^{\prime \prime} \times 16^{\prime \prime}\right)$ was mounted, which was constructed from three different materials to represent the surface reflectivity of typical walls (chipboard, $9 \%$ ), ceilings (museum board, 91\%), and floors (spray painted chipboard, 1\%). The reflectivity was measured for each material using a fiber-optic spectrometer. A window of 4 " $\times 4$ " was made on the wall facing south. Inside the shoebox, a light meter was mounted 8" away from the window and 1-1/4" above from the floor facing the ceiling to measure light levels on a desk space inside the model compartment. Fig. 12 shows the light levels collected at this location for each month at noon with a normal window, with a DDCS without shear actuation, and with a DDCS with shear actuation. There was a large seasonally- 
dependent fluctuation of the light level with normal window (13.4-0.0 lux) representing from high glare conditions to absolutely no light conditions. The daylight autonomy was greatly enhanced by replacing a normal window with DDCS that effectively redistributed the light level to a balanced level (4.4-0.3 lux). The shear actuation of DDCS allowed furthermore increase and balanced light redistribution $(5.3-0.5$ lux).

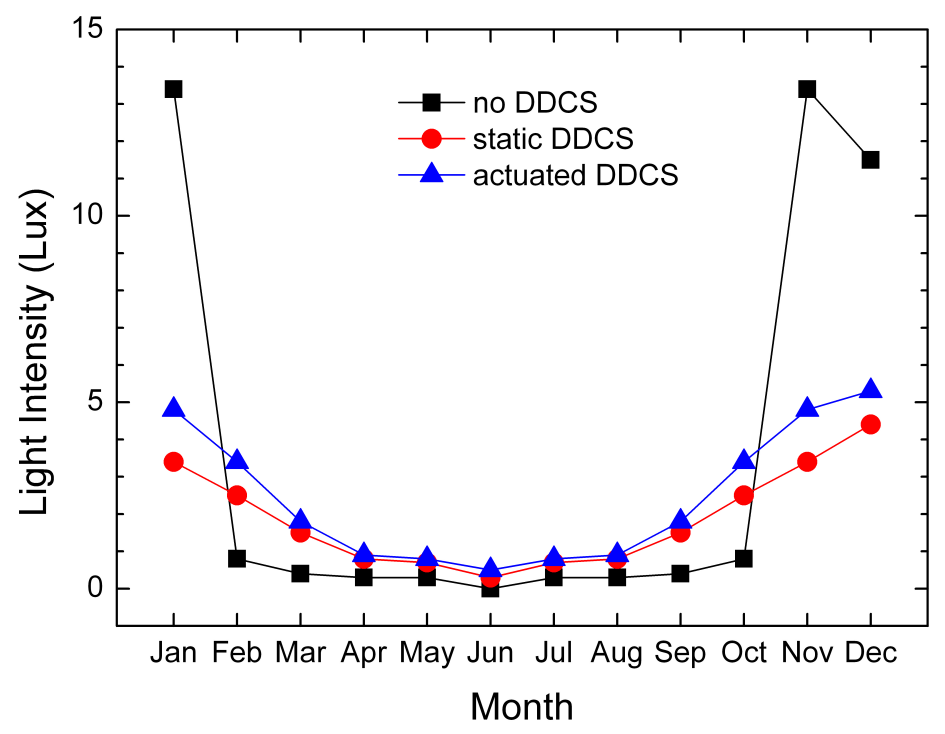

Fig. 12 Light level at the desk level inside a shoebox with standard reflectivity of walls, ceilings, and floors collected without DDCS, with DDCS, and with actuated DDCS (maximum value achieved). A heliodon was used to simulate sun light conditions for Boston, USA ( $42^{\circ}$ North) at noon on the $21^{\text {st }}$ of each month. Note that the data collected for December show large deviation due to the high reflection of the epoxy composite floor of the laboratory where the experiment was setup.

\section{Discussion}

DDCS consists of a single homogenous and elastic PDMS louver layer sandwiched between two panes of glass. During the shear actuation, the PDMS louver changes the angles via elastic deformation. This eliminates the need of mechanical hinges which are one of the main causes of malfunctions in typical adjustable louver systems. The current casting method used to fabricate the PDMS louver sample (Fig. 4) is effective when quickly testing small-scale samples with various configurations and iterations. However, in order to fabricate large-scale, product-quality samples, other fabrication methods such as extrusion also need to be investigated and may be utilized in future stages of development.

A wide range of redirection angles can be achieved with fractional amount of shearing distance (Fig. 6). For example, in order to achieve a 10 degree tilting of the PDMS louvers within a DDCS that is 5 $\mathrm{mm}$ thick, only a $0.882 \mathrm{~mm}$ of displacement in the vertical direction is needed ( $5 \mathrm{~mm} \times$ tangent $(10$ 
degrees) $=0.882 \mathrm{~mm}$ ). The force required for actuating the DDCS is dependent on the thickness, depth and number of louvers as well as the elasticity of the PDMS itself. The shear actuation mechanisms itself (Fig. 14) and the method to integrate it into the DDCS needs to be further investigated as the research progresses toward the product development phase.

Various types of liquid (air, index matching liquid, suspended or pigmented liquid, etc.) can be utilized in the DDCS based on the requirement to achieve a wide range of daylight control functionalities (transmission, redirection, shading, and diffusion). This multi-functionality is significant compared to other existing daylight control systems (Fig. 2). However, further research relating to fluid circulation and control method needs to be conducted in order to efficiently and reliably switch between different states (Fig. 3 and Fig. 7).

The qualitative tests of the DDCS including the laser testing (Fig. 5) and white box testing (Fig. 8) visually show the light redirection effect and its adjustability. Moreover, the quantitative tests including the black tube testing (Fig. 9) and shoebox testing (Fig. 10 and Fig. 11) verified that DDCS is capable of not only redirect light towards the deeper area of the testing boxes but also reduce the light level near the opening itself. This light redistribution effect is significant since exterior clear windows in buildings often cause discomfort to the occupants due to direct penetration of sunlight near the window as well as glare issues caused by the significant luminance differences. More testing will be conducted to further quantify the benefits and limitations of the DDCS.

Finally, although the physical test results explain and verify certain attributes of DDCS, further computational simulation is necessary for the next stage of research. By computationally modeling the material and its effects more accurately and reliably, it will be possible to design the configuration and geometry of the louver based on optimum performance. Furthermore, by utilizing computational simulating methods, it will also be possible to efficiently test and evaluate the DDCS in the various building configuration, climate and location. Finally, it would be also meaningful to evaluate the DDCS (with photo-sensor-controlled lighting system) in terms of energy saving compared to conventional window system.

\subsection{Application}

The DDCS can be either integrated into a new window system or retrofitted to an existing window system. Applications in larger glazed facades are also under investigation. In the new construction window system application, DDCS may be directly attached inside the double pane window cavity. The cavity of the double pane window is utilized as the chamber for the liquid or gas. The cavity of the window frame can house the fluid circulation components and shearing mechanism (Fig. 13 (a)). In the window retrofit situation, DDCS can be attached to one of the glass surfaces of an existing window. In this case, the DDCS needs to be a self-contained unit with sealed fluid chamber, fluid circulation apparatus, and shearing mechanism (Fig. 13 (b)). 


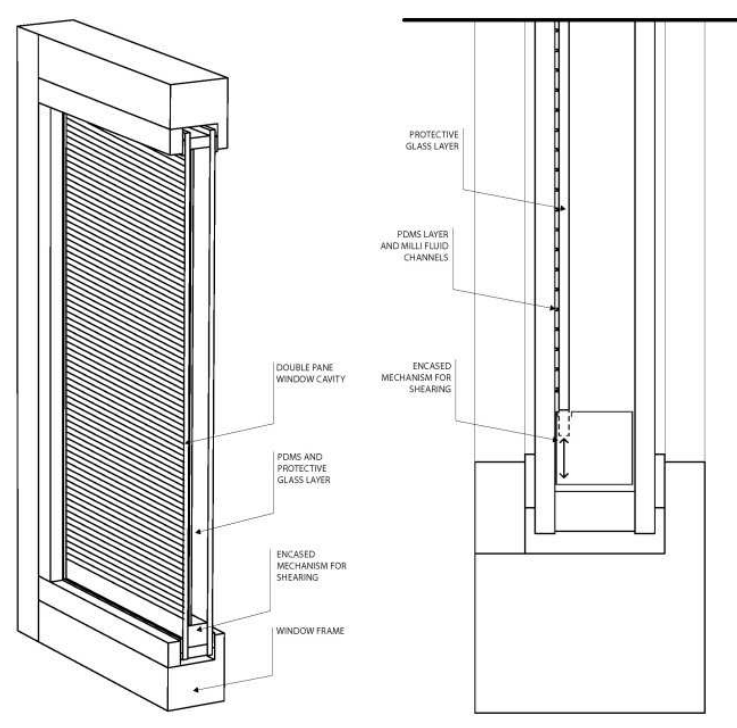

(a)

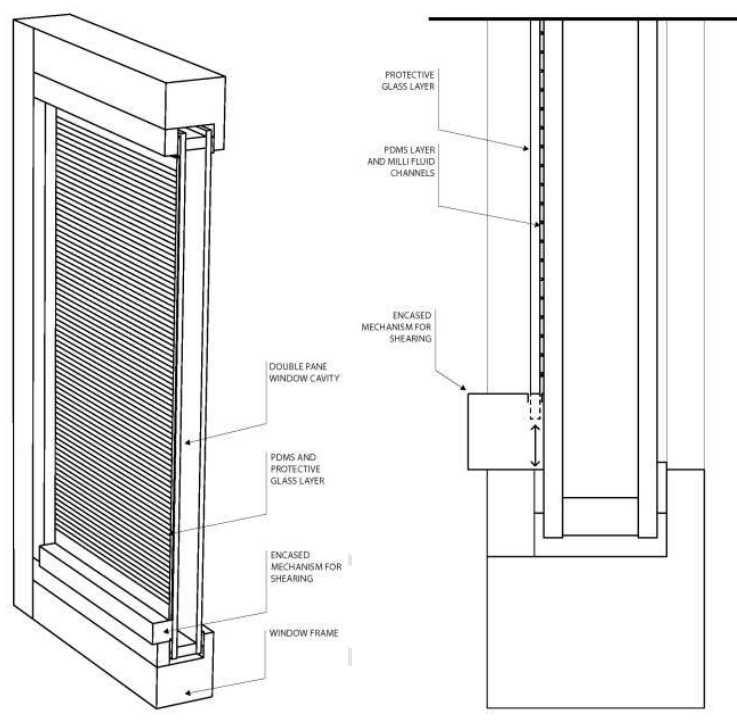

(b)

Fig. 13 Conventional window system application isometric and section: (a) new construction window system and (b) retrofit construction window system.

In both application methods, DDCS can be integrated in different configurations and sizes ranging from full window coverage to only the upper portion coverage of the window (above eye height) to prevent the light being redirected directly to the occupant's eyes. The range of angles, scale and height to depth ratio of the DDCR louvers as well as the fluid types can be customized. These parameters are influenced mainly by the window's direction of exposure, location (e.g. latitude), context (e.g. surrounding buildings), and climate. The shearing actuation mechanism only affects the glass or plastic pane that is inserted within the cavity and the actuation mechanism (Fig. 14) itself can be specified based on factors such as durability, operability, and cost.
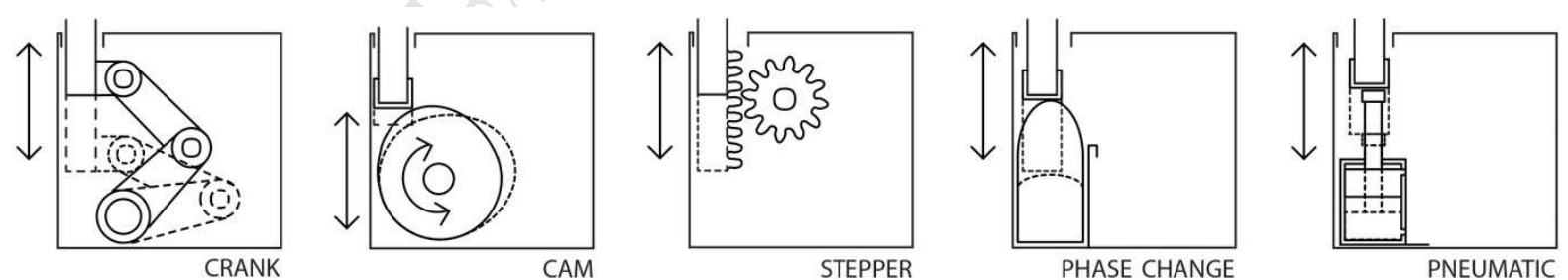

Fig. 14 Possible methods of actuation

\section{Conclusion}

We have demonstrated a daylighting system that can achieve various functionalities within a single layer material system that can be integrated seamlessly in both new window system construction or 
retrofitted to an existing window system. By adjusting the fluid inside the channels of a Dynamic Daylight Control System (DDCS), we have demonstrated three distinct functional states: light redirection state (empty channels), clear state (index matched liquid filled channels), and light dimming state (translucent or opaque liquid filled channels). These states are reversible and dynamically adjustable.

Several iterations of DDCS samples were designed and fabricated utilizing rapid prototyping technology and conventional casting techniques. The characteristics and performance of the samples were tested using both qualitative and quantitative methods and the results verified the core attributes of DDCS. These include dynamic adjustment of the lighting level through filling the channels with different media (air or liquid) and shearing actuation of the PDMS louvers; provide unobstructed view by becoming completely transparent using index matched liquid; and effective light redistribution through reducing the light level in front of the space and redirecting light to the back of the space.

\section{Acknowledgments}

This research is supported by the Wyss Institute for Biologically Inspired Engineering. The project was developed as part of the ongoing interdisciplinary collaboration between members of the Harvard University Graduate School of Design and the Adaptive Material Technologies platform at the Wyss Institute. The authors thank Professor Holly Samuelson for the thorough review of this paper; Allen Sayegh for his contributions throughout; Kevin Hinz and Jeonghyun Kim for fabricating the shoebox testing setup; James Weaver for 3D printing support; and Thomas Blough for the technical input during the early phase of the research. Timor Dogan was instrumental in the development of the initial concept.

\section{References}

[1] Baetens R, Jelle BP, and Gustavsen A. Properties, requirements and possibilities of smart windows for dynamic daylight and solar energy control in buildings: A state-of-the-art review. Solar Energy Materials and Solar Cells 2010; 94.2: 87-105.

[2] Bakker LG, Hoes-van Oeffelen ECM, Loonen RCGM, and Hensen JLM. User satisfaction and interaction with automated dynamic facades: A pilot study. Building and Environment 2014; 78: 4452.

[3] Colaco SG, Kurian CP, George VI, and Colaco AM. Prospective techniques of effective daylight harvesting in commercial buildings by employing window glazing, dynamic shading devices and dimming control-A literature review. Building Simulation 2008; 1.4: 279-289. 
[4] Cupelli C, Nicoletta FP, Manfredi S, Vivacqua M, Formoso P, De Filpo G, and Chidichimo G. Selfadjusting smart windows based on polymer-dispersed liquid crystals. Solar Energy Materials and Solar Cells 2009; 93.11: 2008-2012.

[5] DeForest N, Shehabi A, Garcia G, Greenblatt J, Masanet E, Lee ES, Selkowitz S, and Milliron DJ. Regional performance targets for transparent near-infrared switching electrochromic window glazings. Building and Environment 2013; 61: 160-168.

[6] DiLaura DL, Houser KW, Mistrick RG, and Steffy GR. The lighting handbook. Illuminating Engineering Society; 2011.

[7] DoE, U. S. Buildings Energy Databook. Energy Efficiency \& Renewable Energy Department; 2011.

[8] Fernandes LL, Lee ES, and Ward G. Lighting energy savings potential of split-pane electrochromic windows controlled for daylighting with visual comfort. Energy and Buildings 2013; 61: 8-20.

[9] Galasiu AD, and Veitch JA. Occupant preferences and satisfaction with the luminous environment and control systems in daylit offices: a literature review. Energy and Buildings 2006; 38.7: 728-742.

[10] Hatton BD, Wheeldon I, Hancock MJ, Kolle M, Aizenberg J, and Ingber DE. An artificial vasculature for adaptive thermal control of windows. Solar Energy Materials and Solar Cells 2013; 117: 429-436.

[11] Hocheng H., Huang TY, Chou TH, and Yang WH. A brighter place: overview of microstructured sunlight guide. Journal of Achievements in Materials and Manufacturing Engineering 2010; 43.1: 409-417.

[12] Huang TY, Hocheng $\mathrm{H}$, Chou TH and Yang WH. Bring free light to buildings: overview of daylighting system. In: Mendez-Vilas A ed. Materials and processes for energy: communicating current research and technological developments. Formatex Research Center; 2013.

[13] Ihm P, Nemri A, and Krarti M. Estimation of lighting energy savings from daylighting. Building and Environment 2009; 44.3: 509-514.

[14] Kapsis K, Tzempelikos A, Athienitis AK, and Zmeureanu RG. Daylighting performance evaluation of a bottom-up motorized roller shade. Solar Energy 2010; 84.12: 2120-2131.

[15] Kim JT, Kim G. Overview and new developments in optical daylighting systems for building a healthy indoor environment. Building and Environment 2010; 45.2: 256-269.

[16] Kischkoweit-Lopin M. An overview of daylighting systems. Solar Energy 2002; 73: 77-82

[17] Klammt S, Müller H, and Neyer A. Advanced Daylighting by Micro Structured Components. Berlin: Proceedings of PLDC; 2009.

[18] Klammt S, Neyer A, and Müller HFO. Redirection of sunlight by microstructured componentsSimulation, fabrication and experimental results. Solar Energy 2012; 86.5: 1660-1666.

[19] Koo SY, Yeo MS, and Kim KW. Automated blind control to maximize the benefits of daylight in buildings. Building and Environment 2009; 45.6: 1508-1520.

[20] Kotsopoulos S, Casalegno F, Ono M, and Graybill W. Window Panes Become Smart: How responsive materials and intelligent control will revolutionize the architecture of buildings. SMART (Conference on Smart Systems, Devices and Technologies ) 2012; 112-118. 2012.

[21] Krarti M, Erickson PM, and Hillman TC. A simplified method to estimate energy savings of artificial lighting use from daylighting. Building and Environment 2005; 40.6: 747-754.

[22] Leung TCY, Rajagopalan P, and Fuller R. Performance of a daylight guiding system in an office building. Solar Energy 2013; 94: 253-265. 
[23] Littlefair PJ, Aizlewood ME, and Birtles AB. The performance of use daylighting systems. Renewable Energy 1994; 5: 920-34.

[24] Mayhoub MS. Innovative daylighting systems challenges: A critical study. Energy and Buildings 2014; 80: 394-405.

[25] Meerbeek B, te Kulve M, Gritti T, Aarts M, van Loenen E, and Aarts E. Building automation and perceived control: A field study on motorized exterior blinds in Dutch offices. Building and Environment 2014; 79: 66-77.

[26] Piccolo A, and Simone F. Effect of switchable glazing on discomfort glare from windows. Building and Environment 2009; 44.6: 1171-1180.

[27] Raphael B. Active Control of Daylighting Features in Buildings. Computer-Aided Civil and Infrastructure Engineering 2011; 26.5: 393-405.

[28] Reinhart CF, Mardaljevic J, and Rogers Z. Dynamic daylight performance metrics for sustainable building design, Leukos 2006; 3.1: 1-25

[29] Ruck N, Aschehoug O, Aydinli S, Christoffersen J, Courret G, Edmonds I, et al. Daylight in Buildings. A Source Book on Daylighting Systems and Components; 2001.

[30] Shehabi A, DeForest N, McNeil A, Masanet E, Greenblatt J, Lee ES, et al. US energy savings potential from dynamic daylighting control glazings. Energy and Buildings 2013; 66: 415-423.

[31] Tzempelikos A, and Shen H. Comparative control strategies for roller shades with respect to daylighting and energy performance. Building and Environment 2013; 67: 179-192.

[32] Ucar AM and Velev OD. Microfluidic elastomer composites with switchable vis-IR transmittance. Soft Matter 2012; 8: 11232-11235.

[33] Ullah I, and Shin S. Uniformly illuminated efficient daylighting system. Smart Grid and Renewable Energy 2013; 4.2: 161-166.

[34] Veitch JA, and Galasiu AD. The physiological and psychological effects of windows, daylight, and view at home: review and research agenda; 2012.

[35] Lechner N. Heating, Cooling Lighting: Sustainable Design Methods for Architects, $4^{\text {th }}$ edition. John Wiley \& Sons; 2014. 


\section{Highlights}

- Dynamic Daylight Control System (DDCS) achieve multiple daylight control functions using simple integrated assembly

- DDCS can dynamically redirect incoming daylight through minimal shearing actuation

- Based on the fluid used, DDCS can refract, transmit, diffuse, or absorb incoming light

- DDCS can become completely transparent using index matched liquid

- DDCS can be integrated in new window system or retrofitted to existing windows 